\title{
Super science
}

\author{
The Physics of Superheroes \\ by James Kakalios \\ Duckworth: 2006.384 pp. $£ 9.99$ \\ Death Rays, Jet Packs, Stunts and \\ Supercars: The Fantastic Physics of Film's \\ Most Celebrated Secret Agent \\ by Barry Parker \\ Johns Hopkins University Press: 2005. \\ 231pp. $\$ 25$ \\ A Teaspoon and an Open Mind: The Science \\ of Doctor Who \\ by Michael White \\ Allen Lane: 2005.192 pp. $€ 12.99$ \\ The Science of Doctor Who \\ by Paul Parsons \\ I con Books: 2006.240 pp. $€ 12.99$
}

\section{Stephen Baxter}

Comic-book superheroes might seem an unlikely starting point for a popular book on physics. As James Kakalios relates, the ur-hero Superman was born in 1938 as a Depressionera revenge fantasy - the Man of Steel's first enemies were corrupt landlords and Washington lobbyists. And in the tough darwinian world of pulp comics, the aim of story-telling is to make you turn the page, not scientific accuracy.

But as Kakalios points out, the exploits of a superhero can illustrate scientific principles, although you may need to make a 'miracle exception'. Once you accept that Superman's stablemate the Flash can somehow run at arbitrarily high speeds, then you can study the consequences, such as traction, deceleration forces and nutritional requirements. Indeed, sometimes the comic-book writers explore the science themselves. Kakalios quotes an adventure in which the Flash, in order to save the citizens of a North Korean city from a nuclear blast, runs at close to the speed of light and suffers relativistic effects: "As his body sloughs off the screaming after-effects of near light travel, eyes of almost infinite mass turn towards the blaze engulfing Chongjin." There can be poetry in the physics.

The 'science-of' the latest popular franchise has been a flourishing subset of the popularscience genre since the success of Lawrence Krauss's The Physics of Star Trek (Basic Books, 1995). You can see the appeal for authors and publishers. Fans can be seduced through their curiosity about the infrastructure of their favourite universe - could a machine really travel through time? could a man really fly? into explorations of genuine science. There is thus a benignly educational motive. And, of course, you can sell an awful lot of books to all those fans.

But to get it right you have to focus on the needs of the readership: a fan wants to read a book about the franchise, not a textbook. Of the new crop of such books reviewed here,

\section{IMAGE UNAVAILABLE FOR COPYRIGHT REASONS}

Kakalios's work on superheroes is probably the most successful. He admits to being a fan himself, the text is drenched with fan-friendly references to the comics, and the physics, even when Kakalios points out where the comics got it wrong, is drawn out sympathetically and with good humour.

Barry Parker's study of James Bond's stunts and gadgets is thorough and clearly written, but is something of a plod. You can read about the physics of car chases, but if you're hoping for wild speculation on Bond's invisible car (in the movie Die Another Day) you'll be disappointed. Studded with a lecturer's stories from the classroom, it also has a whiff of chalk dust.

Such is the current popularity of the television series Doctor Who in Britain that it's no surprise to see two new 'science-of' books on the subject. Michael White's tome has an elegant title, based on a Tom Baker line from the show itself " Well, to be fair, I did have a couple of gadgets he probably didn't, like a teaspoon and an open mind." But there simply isn't enough about the Doctor: White's elegantly written but run-of-the-mill essays on time travel and alien life contain only glancing references at top and tail to the Time Lord. Paul Parsons is the editor of the BBC's Focus magazine, and his contribution is snappy, lively, journalistic, has sound bites by various tame boffins, and is drenched in Doctor Who. It $\frac{5}{5}$ is more imaginative too, with explorations of ${ }^{\vec{x}}$ off-beat topics such as the science behind the Doctor's two hearts and his altruism.

The most interesting 'science-of' series is probably that accompanying Terry Pratchett's Discworld books. Written by Jack Cohen and Ian Stewart with Pratchett, the latest is The Science of Discworld III: Darwin's Watch (Ebury Press, 2005), an exploration of darwinism. These books are unique (to my knowledge) in that they contain contributions by the author of the franchise itself. And the authors' intention isn't just to deliver more pop-science books, but to develop ongoing scientific arguments (notably Cohen and Stewart's hypotheses on complexity and intelligence) in a popular form. In that sense these books reach back to an age in which scientists were expected to express their arguments in a form comprehensible to the layman; this is science being done in public.

Not all franchises lend themselves to scientific explorations - not that this deters the attempt. Anyone tempted by The Science of Harry Potter (Roger Highfield; Viking, 2002)? But as a former secondary-school teacher, I can testify to the usefulness of pop-culture examples to snag the student imagination. Spider-Man swinging on his web is a compelling example of a simple pendulum.

Even if they don't snare the fans directly, 'science-of' books can serve as a useful resource for teachers, and when well done can make a valuable contribution to the public understanding and awareness of science.

Stephen Baxter's latest science-fiction novel is Transcendent (Gollancz, 2005).

\section{Incomplete mathematics}

\section{Meta Math! The Quest for Omega \\ by Gregory Chait in \\ Pantheon Books: 2005.223 pp. $\$ 26$}

Ivor Grattan-Guinness

The surprise of Kurt Gödel's incompleteness theorem of 1931 lay not so much in the incompleteness itself, but that it was found in so simple a mathematical theory as first-order arithmetic. It follows, then, that any richer mathematical or logical theory, which is most of them, is also incomplete. In addition, Gödel's method of proof, elaborating what became known as recursive functions, was fruitful in its own right. In particular, it helped in Alan Turing's creation in 1936 of computable numbers and his finding that it cannot be decided in a finite number of steps whether or not a computer can calculate some given number, and whether or not any formula expressible in this system is also a theorem of it.

Turing is Gregory Chaitin's hero, to the extent of being credited with the more general result that it cannot be decided whether or not a computer will complete a given task in some finite number of steps. This extension of Turing's conception, which creates the 'halting problem, actually seems to be attributable to 


\section{EXHIBITION}

\section{Classifying the past}

The photograph of artist Mark Dion
included in hislatest exhibition,
Microcosmographia, is strikingly
similarto one of the American
naturalist William Beebe taken in
1917. This isno accident: Dion's
adoption of the attitudes and
methods of such early naturalists
is very deliberate. Through
Microcosmographia, Dion
highlights problems of accuracy,
past and present, in natural history
and taxonomy.
The exhibition's central piece,
Ichthyosaur, pictured here,
references the confusion of
palaeontological classification
in the early nineteenth century.
Variously misinterpreted by fossil
collectors and palaeontologists as
prehistoric fish, predecessors of
modern crocodiles, or relatives of
the duck-billed platypus, the genus
Ichthyosaurwas only officially
designatedas such by William
Daniel Conybeare in 1822 .
The belly of Dion's life-size resin
replica of a beached ichthyosaur
is split open and over flows with

the paraphernalia of early naturalists, ranging from old reference manuals to glass beakers. The work seems to suggest that the ichthyosaur is a creature quite literally made up of the past; that its inner workings are defined by the humans who discovered it and eventually classified it. The conceptresonates with presentday taxonomy, which is struggling to systematize 250 years of natural history of varying scientific quality: sifting out errors, identifying missed connections, and establishing a comprehensive informatics for the field.

Confusions and corrections, such as those surrounding the ichthyosaur, inspire Dion's work. The diverse collection of sculptures, drawings and photographs in this exhibition, and their juxtapositions and groupings, focus on long-dead scientists and their influences on scientific understanding today. But the collection also raises important

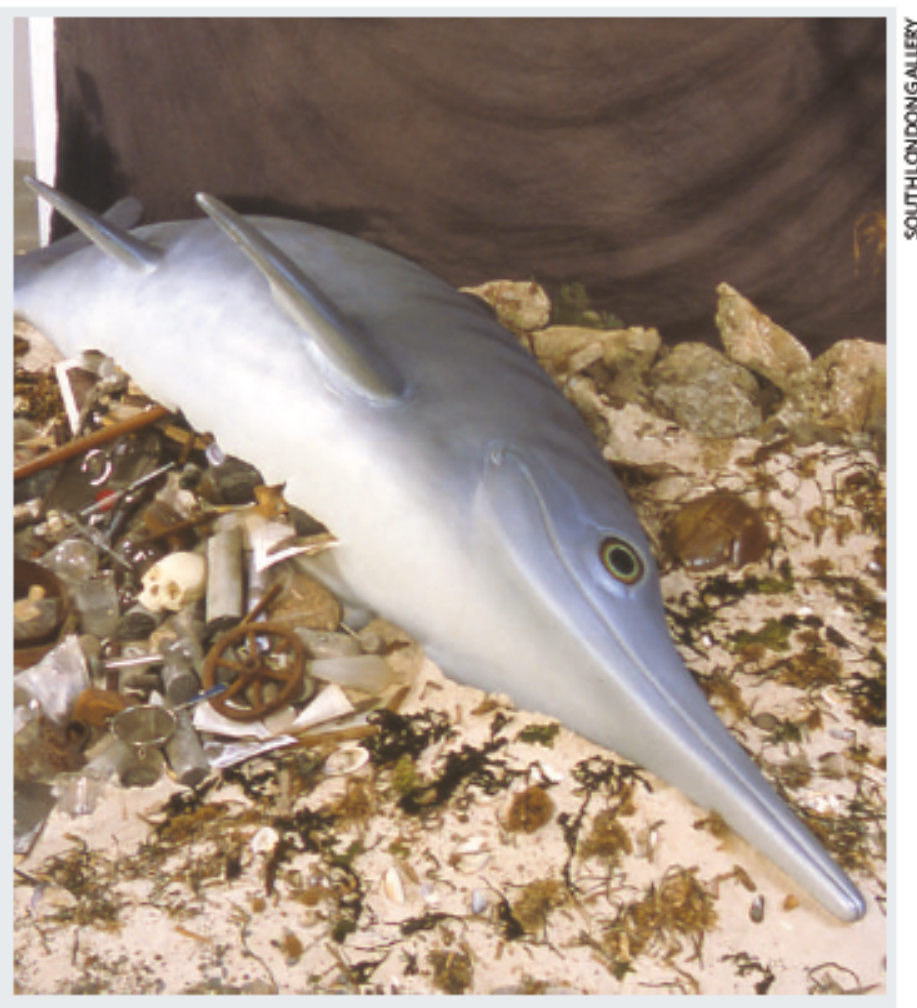

questions about the fallibility of science. Dion seems to want to pointout the mistakes of the past in order to warn us aboutmistakes we might be makingnow, and mightmake in the future.
Microcosmographia, organized by the South London Gallery, can be seen at The Harris Museum and Art Gallery in Preston, UK, until 12 March 2006.

Alexis Clements
Martin Davis in the early 1950s. In Meta Math, Chaitin has extended this line of thought by using the notion of the computer program to study incomplete mathematical theories. Written for the general reader, the book consists of a main text of about 160 pages, followed by reprints of two earlier papers of a more technical character.

A key notion in this book, inspired by biology, is the 'complexity' of a program, specified in terms of the smallest program(s) (in bit size) that can produce some given output. Such a program is irreducible, or incompressible: "So you can define randomness as something that cannot be compressed at all," according to Chaitin. Thence follows the Omega number, an infinitely complex positive real number specifying the halting probability. As Chaitin puts it, it is defined from all the programs chosen by chance to run on a fixed computer and also to continue to run by random operator decisions until the computer "must decide by itself when to stop reading the program"; if a program halts after $k$ bits, then it contributes $1 / 2^{k}$ to the number. As stated, the number depends on the computer used; presumably this machine is Turing-powerful enough to run any program installed on it. Drawing upon a discussable daim that any mathematical theory can be encoded in programming terms, Chatin concludes that the Omega number "marks the current boundary of what mathematics can achieve".

Chatin's investigation is attended by several skirts around paradoxes, especially those involving naming. For example, to qualify as a program contributing to the Omega number, the program has to be able to say how large it is when it halts. This type of concern also owes much to Godel's 1931 theorem, where new standards were imposed on distinguishing logic from metalogic. It is a pity that Chaitin never states that theorem precisely, and once even states it quite wrongly.

The scope of the author's meta-programme (as it were) is impressive: essentially straightforward assumptions and steps lead to some wide-ranging consequences and claims about mathematics, logic and computing science. The account is nicely signposted by the frequent use of information boxes containing the main definitions, steps or relationships. As the book is intended for a wide audience, it might have been enriched by some comments on concurrent developments that have used versions of the main notions, for example, (non-biological) complexity with A. N. Kolmogorov in the $1960 \mathrm{~s}$, or the realm of intelligent activity lying beyond computability, as debated by Roger Penrose and others in recent times.
The style of writing throughout is better suited to an internet chatroom than to a book ( ${ }^{\alpha}$ Discours de Métaphysique — that's the original French" is only one such example) and has exclamation marks spread liberally. Instead of properly referencing works that are precisely cited in the text, " $\mathrm{I}$ decided to concentrate mostly on recent books that caught my eye," says the author. The list lacks, among other key works, J. W. Dawson's Logical Dilemmas, The Life and Work of Kurt Godel (A. K. Peters, 1997) and The Essential Turing edited by B. J. Copeland (Oxford University Press, 2004).

Many historical remarks are made, but are seemingly free of knowledge of the figures involved and their importance. For example, "the nearly-forgotten 17th-century genius Leibniz", "Newton's incomprehensible Principia - written in the style of Euclid's Elements", or "it was Cantor's obsession with God's infiniteness and transcendence that led him to create his...theory of infinite sets and infinite numbers". The reader should be ready to add their own exclamation marks to such passages.

It is nice to have popular books on modern mathematics, logic and science. But it is nicer if they are prepared with care. Ivor Grattan-Guinness is at Middlesex University, Enfield, Middlesex EN3 4SF, UK. 